\title{
Turismo e voluntariado: a busca pela compreensão do volunturismo
}

\section{Tourism and volunteering: the search for understanding of the voluntourism}

Pablo Braga de Souza, Antônia Maria Nascimento Barcelos, Suellen Alice Lamas

RESUMO: Ao longo do tempo, o turismo tem se destacado como uma importante atividade econômica no mundo, gerando serviços, produtos, emprego e renda. Entretanto, tão importante quanto o seu potencial econômico, é o seu potencial social, capaz de transformar localidades que apresentam desequilíbrios e limitações, o que vem sendo proposto pelo turismo voluntário também conhecido como volunturismo. Embora seja muito praticada no exterior, essa modalidade, está em estágio inicial no país, o que traz à tona dúvidas e questionamentos em relação ao tema e a necessidade de estudá-lo a fim de que se possa compreendê-lo em sua totalidade. Deste modo, faz-se a reflexão: O que é turismo voluntário? Qual o perfil do público que o pratica? Quais as diferenças entre turismo voluntário e turismo solidário? Quais os impactos nas comunidades visitadas? A partir desses questionamentos, 0 presente trabalho visa discorrer sobre 0 turismo voluntário apresentando suas interfaces conceituais, problemáticas e perfil dos praticantes, de modo a contribuir com o esclarecimento e debate teórico sobre o tema. Assim, vê-se a importância de estudos em relação ao turismo voluntário para que, a partir de sua compreensão, os resultados positivos possam ser maximizados e os negativos minimizados. Baseando-se em seu caráter de agente transformador social, pode-se inferir que o turismo voluntário é mais uma forma de se fazer turismo, contrária ao turismo de massas, do que um segmento propriamente dito.

PALAVRAS-CHAVE: Voluntariado; Turismo; Conhecimento; Volunturismo. 


\section{ABSTRACT}

Over time, the tourism has distinguished itself as an important economic activity in the world, generating services, products, employment and income. However, as important as its economic potential, it is its social potential capable of transforming localities that show unbalances and limitations, what has been proposed by the volunteer tourism also known as voluntourism. Although it has been practiced abroad, this type of tourism is in an early stage in the country, which propitiates doubts and questions concerning the theme and the necessity to study it in order to understand it in its entirety. Thus, the reflection is done: What is volunteer tourism? What is the public profile that practices it? What are the differences between volunteer tourism and solidary tourism? What are the impacts on the communities visited? Based on these questions, the article aims to discuss about volunteer tourism showing its conceptual interfaces, problematic and the profile of the participants in order to contribute to the elucidation and the theoretical debate on the subject. Therefore, one sees the importance of the studies concerning volunteer tourism so that, from its understanding, positive results can be maximized and negative results can be minimized. Based on its character of a social transforming agent, one can infer that the volunteer tourism is more a way of doing tourism, contrary to mass tourism, than a segment itself.

KEYWORDS: Volunteering; Tourism; Knowledge; Voluntourism.

\section{Introdução}

A sociedade está em constante transformação. De tempos em tempos, emergem novas demandas que se apresentam como problemáticas e indagações que devem ser refletidas e trabalhadas pelos diversos setores sociais. O turismo, enquanto um fenômeno social, também deve se adequar àquelas. Neste sentido, respondendo a uma demanda atual, a atividade vem assumindo uma postura mais racional e de responsabilidade socioambiental. Corroborando tal afirmação, a Organização Mundial do Turismo considera que a motivação e o comportamento dos turistas são caracterizados, cada vez mais, pela seletividade na escolha dos destinos, pela sensibilidade ao meio ambiente e cultura locais, e pela exigência de qualidade da experiência (WTO, 2011).

O comportamento psicossocial dos principais mercados turísticos receptores está motivado pela atração, retenção e repetição dos fluxos turísticos das regiões emissoras e busca satisfazer as necessidades físicas e psíquicas dos turistas, tais como o descanso, a aventura, os encontros culturais ou a autorrealização no tempo de ócio disponível, sustentado por um tempo livre, um destino turístico e um orçamento que permita conseguir uma boa qualidade de serviços a um preço realmente favorável. O turista, por sua vez, pretende conhecer mais destinos, ser protagonista de suas férias, alcançar uma maior autorrealização e buscar um contato direto com a natureza no menor tempo possível (BARRETO, 2005). Definitivamente, o turista mudou de uma atitude passiva para uma ativa, o que se refletiu na própria atividade turística. 
Neste contexto de mudanças e adequações, surgem novas modalidades turísticas, baseadas nas demandas de mercado, cada vez mais inteiradas e participativas. O presente trabalho versará sobre uma dessas novas modalidades, o turismo voluntário, que consiste em o turista colaborar em alguma causa significativa na localidade visitada durante a viagem.

O turismo voluntário se apresenta como uma atividade mais consciente, no qual se pensa em transformar positivamente o destino escolhido. Essa modalidade é também conhecida como volunturismo, neologismo criado nos anos 1990 a partir da junção dos termos da língua inglesa volunteer e tourism, traduzidos para a língua portuguesa como voluntário e turismo (NUNES, 2015).

Embora seja muito praticada no exterior, essa modalidade, começa a dar seus primeiros passos no país, o que traz à tona dúvidas e questionamentos em relação ao tema e a necessidade de estudá-lo a fim de que se possa compreendê-lo em sua totalidade.

Diante desse contexto, faz-se a reflexão: o que é turismo voluntário? Qual o perfil do público que o pratica? Quais as diferenças entre turismo voluntário e turismo solidário? Quais os impactos nas comunidades visitadas?

A partir desses questionamentos, o presente artigo visa discorrer sobre o turismo voluntário apresentando suas interfaces conceituais, impactos locais e perfil dos praticantes, de modo a contribuir com 0 esclarecimento e debate teórico sobre o assunto.

No presente artigo foi desenvolvida uma pesquisa exploratória, de modo que se conseguisse uma maior proximidade com o tema. Em relação aos procedimentos técnicos, realizou-se uma pesquisa bibliográfica a partir da busca de materiais publicados em livros, artigos e sítios eletrônicos. A abordagem foi qualitativa, em que os dados coletados foram predominantemente descritivos e baseados em realidades múltiplas. $O$ texto foi elaborado com as conclusões tiradas a partir dessas leituras, incluindo registros eletrônicos.

A relevância deste artigo se dá pela ausência de estudos na área, em especial aqueles com abordagem teórica, pois apesar de ser uma prática mundialmente conhecida, o turismo voluntário ainda é incipiente no Brasil apresentando "(...) carência de bibliografia acadêmica e/ou especializada em nível nacional que esclareça e explique tal prática” (MENDES; SONAGLIO, 2013, p.186).

\section{Turismo voluntário: conceitos, importância e impactos}

\section{Turismo Voluntário Mundial: caracterização histórica e conceitual}

À frequente necessidade de transformação e adaptação humanas, faz-se observar o crescimento populacional e o desenvolvimento econômico mundial que fizeram aumentar o consumo médio da humanidade. De acordo com Alves (2010, p.24): 
(...) Entre 1800 e 2010 a população mundial cresceu, aproximadamente, sete vezes (de 1 bilhão para 7 bilhões de habitantes) e a economia (PIB), aumentou cerca de 50 vezes. Mas o crescimento da riqueza se deu à custa da pauperização do planeta.

Como consequência, a sociedade atual, busca soluções para esses problemas, norteada pelo princípio do desenvolvimento sustentável, que segundo o Relatório Brundtland, intitulado Our Future Commom é "o desenvolvimento que satisfaz as necessidades do presente sem comprometer a capacidade das gerações futuras de satisfazerem suas próprias necessidades" (WCED, 1987).

Deste modo, a sustentabilidade mostra-se como um grande desafio para o século XXI. Para Sachs (2008) este desafio engloba a proteção ao meio ambiente, a estabilidade do crescimento populacional mundial e a redução das diferenças econômicas e sociais, o que exigirá uma mobilização global, fundamentada na cooperação, em muitos casos, voluntária de todos os envolvidos.

$\mathrm{Na}$ esteira destas mudanças, portanto, é que o voluntariado ganhou força, refletindo-se inclusive, nas práticas turísticas. Neste sentido, o turismo voluntário ou volunturismo:

(...) apresenta-se no contexto atual como um promissor mercado para os próximos anos, que compreende práticas sustentáveis e gera benefícios para os que delas participam: o turista, o ambiente e a comunidade (MENDES; SONAGLIO, 2013, p.186).

Para se entender melhor o volunturismo, faz-se necessário, antes, compreender os conceitos de voluntário e voluntariado. Segundo definição da Organização das Nações Unidas:

(...) voluntário é o jovem, adulto ou idoso que, devido a seu interesse pessoal e seu espírito cívico, dedica parte do seu tempo, sem remuneração, a diversas formas de atividades de bem estar social ou outros campos (ONU BR, 2016).

O voluntariado, por sua vez, "(...) parece se definir como um conjunto de ações, desenvolvidas sem intenção financeira, ao menos manifesta, envolvendo algum tipo de doação (tempo, dinheiro, conhecimento etc.)" (GROPPO; ZAMARIAN, 2009, p.2).

Esse tipo de atitude é reflexo de uma sociedade que, cada vez mais, assume um compromisso com a responsabilidade social. E, que, ao agir desta forma, não só contribui para a construção de um mundo mais justo, como também, e principalmente, cresce com o aprendizado adquirido nestas novas experiências. 
O turismo voluntário, da forma como se apresenta atualmente, é uma prática recente na história mundial. Apesar de se encontrar exemplos pontuais em diferentes épocas, não há um registro exato de sua origem. Há autores que atribuem seu surgimento à década de 80 e sua expansão à década de 90 (MENDES; SONAGLIO, 2013).

Sobre o conceito de turismo voluntário, a organização VolunTourism ${ }^{1}$, esclarece que, num sentido mais amplo, o volunturismo representa as experiências de voluntariado que incluem viagens para um determinado destino, a fim de realizar um trabalho ou serviço, e, numa abordagem mais específica, volunturismo é a combinação integrada do serviço voluntário para um destino com os elementos tradicionais de viagens e turismo - artes, cultura, geografia, história e recreação (VOLUNTOURISM, 2016). De acordo com dados da Association for Tourism and Leisure Education and Research (ATLAS, 2008) o mercado de volunturismo tem crescido rapidamente, com demanda anual de 1,6 milhões de turistas que geram receitas entre US\$1,6 e US $\$ 2,6$ bilhões em suas viagens pelo mundo.

Como principais emissores de volunturistas tem-se os Estados Unidos da América (EUA) e a Europa e, como destinos receptores, países latinoamericanos - Peru, Cuba, Bolívia, Equador, Honduras, El Salvador, Nicarágua, Brasil, México e Guatemala; africanos - Marrocos, Senegal, Tanzânia e Mali; e asiáticos - China, Camboja, Taiwan e Índia (Figura 1) (PORTAL DE AMÉRICA, 2011).

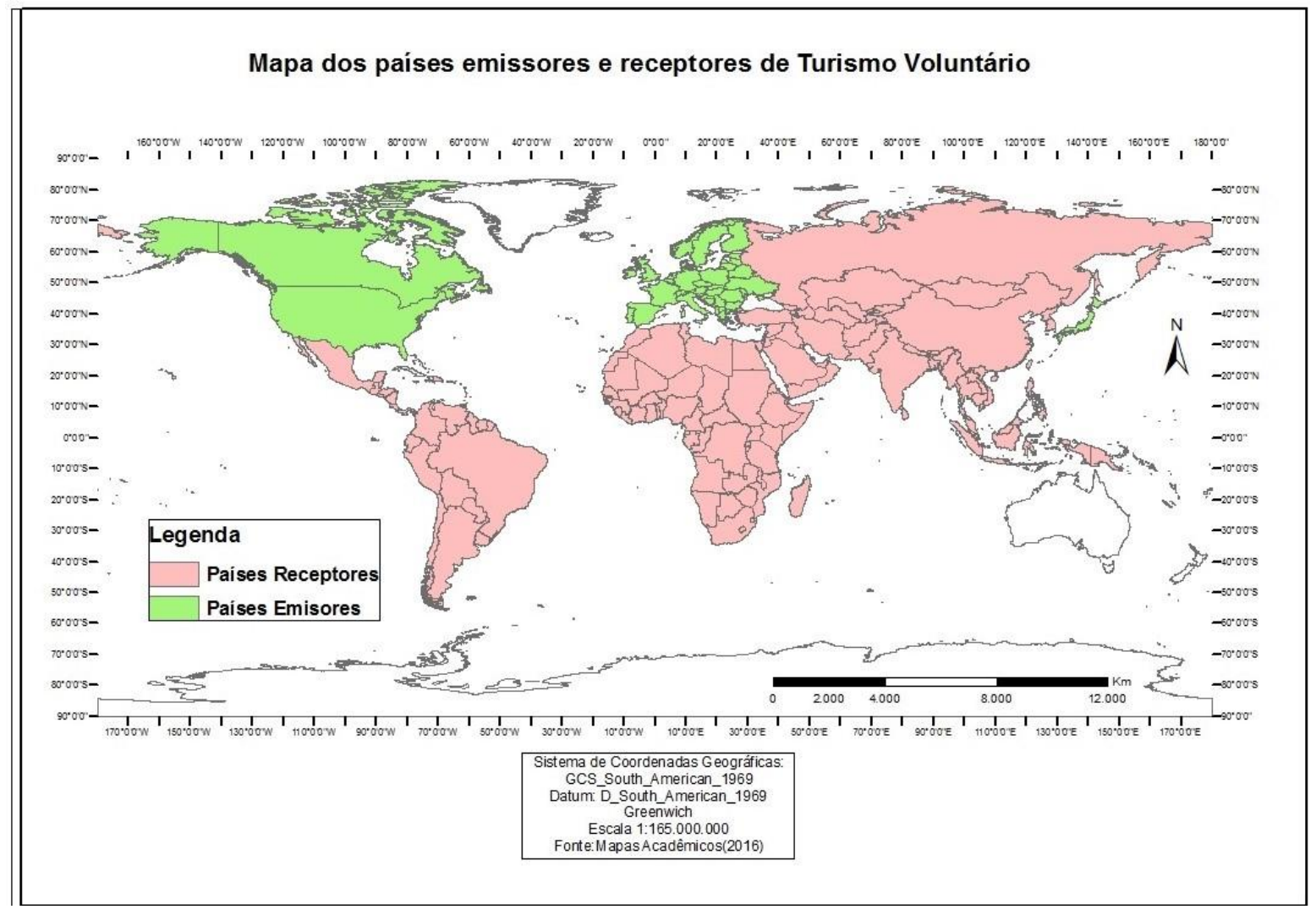

Figura 1: Mapa dos países emissores e receptores de Turismo Voluntário.

Fonte: Adaptado de Mapas Acadêmicos (2016).

Figure 1: Map of the emitting and receivers countries of the Volunteer Tourism.

Source: Adapted from Academic Maps (2016). 
O turismo voluntário se forma com base em quatro elementos: a participação ativa do turista voluntário, a busca espontânea pelo projeto, a falta de motivação de ganhos financeiros e a busca pelo bem comum (ECOD, 2012).

As áreas para atuação no volunturismo incluem: a) ação social, ajudando refugiados de guerra, saúde, sem-teto, mulheres em risco de exclusão, direitos de povos indígenas, etc.; b) ecologia e meio-ambiente, recuperando e conservando a fauna e a flora; c) apoio na administração e gestão de organizações ou busca de financiamento; d) cooperação em projetos de sensibilização e captação de fundos; e) emergências, ajudando em crises e catástrofes; f) cultura, organizando atividades em espaços ou entidades relacionadas à cultura (GÓMEZ; CANALS, 2012).

Ao redor do mundo, encontram-se diversos exemplos da dupla turismo- voluntariado, sendo a Assistência Médica Internacional (AMI) um dos mais reconhecidos projetos com esse viés. A AMI, fundada em 1984, em Portugal, e atuante em 79 países, desenvolve três grandes tipos de intervenções: missões de emergência, missões de desenvolvimento com equipes expatriadas e Projetos Internacionais em Parceria com Organizações Locais (PIPOL), procurando adequar a sua atuação às características e necessidades do contexto, assumindo para tal uma intervenção faseada, tendo sempre como objetivo, a sustentabilidade do processo de desenvolvimento (AMI, 2016). Outro destaque é a Global Volunteers, fundada na década de 1980, nos EUA, atuante em mais de 30 países, se empenha em criar, nutrir e sustentar o bem-estar das crianças, bem como o ensino da língua inglesa. Ao ajudar com projetos abrangentes de saúde, nutrição e educação, contribui de forma única com a comunidade (GLOBAL VOLUNTEERS, 2016.).

\section{Turismo Voluntário no Brasil}

Segundo pesquisa sobre voluntariado, encomendada em 2014 pela Fundação Itaú Social ao Instituto Datafolha, apenas $11 \%$ da população brasileira realiza alguma atividade voluntária, ou seja, cerca de 16 milhões de pessoas se doam, sem remuneração, em prol de alguma obra ou projeto (TRIGUEIRO, 2014).

Como um incremento para essa prática, foi criada a Lei 9608 de 18 de fevereiro de 1998, que regulamenta a atividade, ao considerar serviço voluntário:

a atividade não remunerada, prestada por pessoa física a entidade pública de qualquer natureza, ou a instituição privada de fins não lucrativos, que tenha objetivos cívicos, culturais, educacionais, científicos, recreativos, ou de assistência social, inclusive mutualidade (BRASIL, 1998).

Segundo o Relatório de Desenvolvimento Humano da Organização da Nações Unidas (ONU) de 2015, o Brasil está numa categoria de "desenvolvimento humano elevado". Apesar desse fator, a entidade esclarece que nem toda a população brasileira vive com os mesmos níveis 
de desenvolvimento, ressaltando que ainda há uma elevada desigualdade social no país, característica que o transforma em grande alvo do turismo voluntário (PNUD, 2015).

Diferentemente do exterior, no Brasil existe um fenômeno bem similar ao turismo voluntário intitulado de turismo responsável, social, consciente ou, mais comumente utilizado, solidário.

O turismo solidário tem como proposta a valorização da cultura e belezas naturais locais, a troca de conhecimentos e geração de renda para às comunidades. Segundo Marques (2013):

Assim como o volunturista, o que move o turista solidário é a mesma necessidade de ajudar o outro. Embora sua troca com o destino seja de forma mais sutil, a ponte entre o local e o viajante é feita em prol de causas sociais. O turista solidário é consciente de sua importância como ferramenta para ajudar no desenvolvimento local de forma participativa, de acordo com sua disponibilidade, sem um compromisso de interação direta ou a longo prazo.

Em outras palavras, ainda citando a autora, "o turista solidário oferece - que pode, ao contrário do voluntário que oferece o que necessita" (MARQUES, 2013).

Ainda em fase de expansão no país, ambas as tipologias de turismo supracitadas, beneficiam as regiões mais carentes do território brasileiro e se apresentam em forma de projetos mais pontuais e específicos. No Brasil, as ajudas se configuram, basicamente, em projetos sociais e de preservação da natureza.

Destaca-se a Volunteer Vacations (VV), primeira agência brasileira com foco em turismo voluntário, fundada em abril de 2014. A agência atua em mais 12 países, tendo como destinos mais procurados para essa prática o Quênia, Tailândia, Brasil e Haiti. A empresa conta com 13.000 pessoas cadastradas e tem como hábito a realização de ações que ocorrem todos os meses a nível nacional e uma vez por ano, durante uma semana inteira, a nível internacional. Como exemplo de sucesso tem-se a formação de 300 empreendedores na maior comunidade da África em Kibera no Quênia. (SERRA, 2016).

No Brasil, a agência desenvolve projetos em parceria com as ONGs: no Rio de Janeiro, a ONG Adaptsurf, fundada em 2007, com a proposta de desenvolver o surfe adaptado para pessoas com deficiência, lutar pela preservação e por melhorias na acessibilidade das praias, garantindo a inclusão social; Amparando JG, ONG criada em 2014, com o objetivo de acolher as famílias em situação de extrema pobreza e risco social, localizada na comunidade Jardim Gramacho. Em Pernambuco, o Ciranda Sertaneja, fundada em 2015, com a proposta de promover o gosto pela leitura através da contação de histórias, teatro e música na cidade de Manari; em Goiás, a No Extinction-Nex, fundada em 2000, com o objetivo de defender e preservar os felídeos da fauna silvestre brasileira em processo de extinção. 
Resgata, abriga e trata animais silvestres vítimas de caças, exploração e maus tratos e cativeiro ilegal (SERRA, 2016).

Para Mariana Serra (2016), o número de interessados na prática do turismo voluntário, tem crescido bastante e, com isso, modificando o perfil dos seus clientes, que hoje é composto em sua maioria por mulheres, cerca de $98 \%$.

As principais agências de turismo voluntário oferecem pacotes que incluem acomodação, refeições, transportes, e atividades previamente planejadas, nos destinos escolhidos (MAZZI, 2016).

Como exemplos de organizações que trabalham com turismo solidário, a Raízes do Desenvolvimento Sustentável oferece roteiros de imersão cultural, incluindo oficinas de artesanato, acomodações e refeições em Minas Gerais e a Rede Tucum que organiza, divulga e discute projetos de turismo comunitário e solidário principalmente pelo Nordeste (MAZZI, 2016).

\section{Perfil do turista voluntário}

Para melhor entender o perfil do volunturista, é interessante analisar, primeiramente, a Pirâmide de Maslow (Figura 2) que representa a teoria da motivação ou teoria das necessidades proposta por Abraham $\mathrm{H}$. Maslow. Essa teoria se baseia na hierarquia das necessidades humanas, ou seja, essas necessidades estão organizadas em níveis de importância e influência do comportamento humano. Na base da pirâmide estão as necessidades primárias de segurança e fisiológicas, posteriormente tem-se as necessidades secundárias: sociais, estima e autorrealização, consideradas as mais elevadas (CHIAVENATO, 2008).

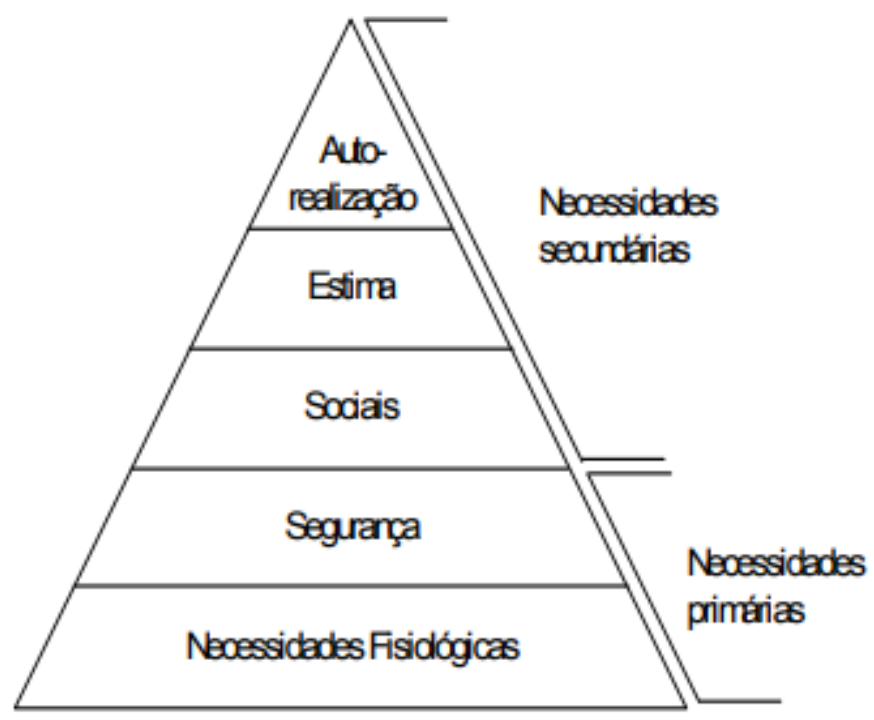

Figura 2: Pirâmide de Maslow. Fonte: Chiavenato (2008). Figure 2: Maslow's pyramid. Source: Chiavenato (2008). 
As necessidades primárias compreendem as necessidades fisiológicas que são inatas, nasceram com o indivíduo (alimentação, repouso, abrigo e sexual); e as necessidades de segurança que conduzem as pessoas a se protegerem de perigos reais ou imaginários, físicos ou abstratos. Tendo sido satisfeitas estas, busca-se pelas necessidades secundárias, sendo a primeira delas, as necessidades sociais relacionadas ao convívio social, aceitação, associação, trocas de amizades, afeto e amor; as necessidades de estima, na sequência, estão ligadas com a autoavaliação e autoestima, com a necessidade de reconhecimento, reputação e prestígio; e finamente, no nível mais elevado das necessidades, está a de autorrealização, relacionada à necessidade de autonomia, independência, plena realização. Ao contrário das demais que seriam satisfeitas por fatores externos, as necessidades de autorrealização refletem satisfações internas e levam as pessoas a desenvolverem continuamente seu próprio potencial (CHIAVENATO, 2008).

É possível correlacionar a teoria da motivação com o turismo voluntário uma vez que as motivações que influenciam o comportamento humano estão relacionadas às suas próprias necessidades. Assim, doar-se a uma causa social ou ambiental no destino visitado, motivações para o turismo voluntário, estaria relacionado à uma necessidade secundária desse turista, seja ela social, de estima ou, principalmente, de autorrealização.

Para Andereck et al. (2012) não há um único perfil de turista voluntário, mas há características comuns que tendenciam esse perfil. Em termos demográficos, as mulheres são mais propensas a participar do turismo voluntário. Uma grande parte tem entre 35 e 44 anos. Os níveis de educação variam, mas muitos volunturistas possuem educação superior. A diferença entre estes e os turistas de massa seria o envolvimento com a comunidade, logo, os níveis de intensidade psicológica e emocional seriam maiores.

Segundo Callanan e Thomas (2005 apud MENDES; SONAGLIO, 2013), há três níveis para categorizar os volunturistas: no primeiro nível, encontra-se o turista que apesar de fazer trabalho voluntário, tem como prioridade a busca de seu crescimento pessoal; no segundo nível, está o turista voluntário que se envolve mais na realidade do destino, porém ainda busca o autoconhecimento; e no terceiro nível é onde se encontra os turistas altruístas, aqueles que realmente tem como objetivo principal, ajudar, beneficiar os destinos visitados.

\section{Problemáticas do Turismo Voluntário}

O turismo voluntário, assim como os demais segmentos turísticos, não está isento de impactos negativos, ainda que considerado um turismo sustentável. Neste sentido Frossard (2004, p.1) contribui que: 
O fenômeno turístico tem uma incrível capacidade de modificação do ambiente e da economia da destinação onde ele se instala. No entanto, muito diferente do que tem sido propagado sobre os benefícios do turismo, esse também é responsável por trazer diversos impactos negativos à localidade e à comunidade local. Muitas vezes esses prejuízos são camuflados ou escondidos pelos fantásticos números de empregos e receitas gerados pelo turismo. Entretanto, os impactos, quer positivos ou negativos, precisam ser verificados, para que na elaboração de um plano de desenvolvimento do turismo, os aspectos positivos sejam ressaltados e os negativos minimizados.

Por essa razão, faz-se necessário conhecer os impactos positivos e negativos gerados pelos volunturistas. Impactos são, segundo Ruschman (2000, p. 34):

(...) consequência de um processo complexo de interação entre os turistas, as comunidades e os meios receptores. Muitas vezes, tipos similares de Turismo provocam diferentes impactos, de acordo com a natureza das sociedades nas quais ocorrem.

Para Souza e Panzini (2008 apud MENDES; SONAGLIO, 2013) o turismo voluntário impacta positivamente a economia e comunidade locais à medida que promove a paz mundial pelo intercâmbio entre os povos, melhora as condições de vida e distribui a renda nos destinos. Por outro lado, para Guttentang (2009), a prática tem efeitos negativos ao negligenciar os anseios da comunidade local, concluir um trabalho insatisfatório, gerar mudança cultural e diminuir a procura por trabalho causando a dependência dos moradores.

Com relação aos volunturistas, para além de motivos altruístas podem haver motivações egóicas que geram uma visão de superioridade daqueles, atitude tida como colonialista e imperialista que leva a uma dominação unilateral e exploração das comunidades visitadas (INGRAM, 2008). Ainda, segundo Sin (2009), este tipo de turismo que naturalmente atrai turistas a áreas pobres, levanta grandes questões sobre se o volunturismo promove um certo "voyeurismo da pobreza". O ato voyeur consiste na prática de observar o outro e sentir prazer, neste caso, pessoas em situação inferior, necessitando de ajuda.

Com a mesma visão crítica do volunturismo, Birrel (2010) afirma que:

(...) a dura verdade é que o "volunturismo" é mais sobre a autorrealização dos ocidentais do que as necessidades dos países em desenvolvimento. Talvez isso não seja surpreendente em um mundo em que Madonna acha que é bom levar crianças de famílias africanas (BIRREL, 2010, tradução nossa). 
As problemáticas do turismo voluntário apresentadas são sintetizadas na Tabela 1.

Tabela 1: problemáticas do turismo voluntário.

Table 1: problematics of the volunteer tourism.

\begin{tabular}{|l|l|}
\hline \multicolumn{1}{|c|}{ Pontos Positivos } & \multicolumn{1}{c|}{ Pontos Negativos } \\
\hline Estabelecimento de laços de solidariedade & $\begin{array}{l}\text { Autorrealização em detrimento das } \\
\text { necessidades }\end{array}$ \\
\hline Defesa dos mais altos ideais & Neocolonialismo \\
\hline Promoção da Paz Mundial & Desrespeito aos costumes e tradições locais \\
\hline Melhoria das condições de vida & Negligência de anseios da comunidade local \\
\hline Promoção da sustentabilidade & Voyeurismo da pobreza \\
\hline & $\begin{array}{l}\text { Fonte: Próprio autor. } \\
\text { Source: }\end{array}$ \\
\hline
\end{tabular}

\section{Reflexões e considerações finais: uma visão crítica do turismo voluntário}

Por ser um tema em exploração e com material acadêmico ainda em construção, principalmente no Brasil, faz-se necessário aprofundá-lo com pesquisas, visto que, como toda atividade turística, o turismo voluntário também é bastante complexo, pois envolve várias áreas da sociedade, ficando, também, sujeito a alterações de cunhos econômico, político e social.

Baseando-se em todos os aspectos apresentados, o turismo voluntário pode ser considerado uma nova versão do turismo e, ao contrário do turismo de massa, é conduzido pela comunidade, procurando beneficiar, ao mesmo tempo, hóspedes, hospedeiros, o meio ambiente, a cultura e os costumes locais.

Embora se apresente como uma nova modalidade, pode-se aferir que o turismo voluntário é mais uma forma de se fazer turismo, do que um segmento propriamente dito, isto porque ele pode ser praticado dentro do ecoturismo, do turismo religioso, do turismo cultural e de outros segmentos, desde que suas bases sejam mantidas: participação ativa do voluntário, busca espontânea pelo projeto, sem motivação de ganhos financeiros e a busca pelo bem comum.

Analisando o ciclo do volunturismo de forma global, percebe-se que, quando a atividade não atinge seus objetivos, na maioria das vezes, é por pouca ou nenhuma responsabilidade do voluntário em desempenhar as atividades propostas pelo projeto, tornando sua participação pouco eficiente, ou apenas por vontade de agregar valores ao seu currículo, ou ainda por tentar imitar as celebridades em fotos de ações humanitárias.

As pessoas responsáveis por instituições também podem promover a falta de sucesso, por desvio de conduta, se prevalecendo dos valores pagos pelos voluntários e não os direcionando corretamente e até supervalorizando as experiências, tentando adaptar a atividade turística aos interesses dos turistas, acabando por promover um processo sem benefícios a nenhum dos lados. 
Pode ocorrer também que, a experimentação das atividades cotidianas da comunidade visitada, em conjunto com a troca de saberes com os visitantes, acabe não existindo e resulte em mudanças nos costumes tradicionais, chegando a banalizá-los. Deste modo, ocorre certa frustação devido às diversas expectativas criadas, talvez por falta de informação na descrição do projeto ou por omissão de detalhes, ou ainda por falta de formação ou preparo do voluntário, antes de vivenciar a experiência.

Há críticas também a respeito do perfil dos voluntários, quando estes, sem preocupação com planejamento e com pouca motivação em participar das atividades, preocupa-se mais com a viagem propriamente dita, o que pode gerar um comportamento egóico e não altruísta.

Como a atividade em geral, é intermediada por ONGs, se faz necessária uma pesquisa sobre a idoneidade das mesmas e do seu histórico, a fim de que não ocorram problemas ou prejuízos futuros.

Sendo o fator social uma constante nesse tipo de turismo, é imprescindível que o turista tenha um maior compromisso na escolha do destino a ser visitado, pois vivenciará situações em locais muitas vezes inóspitos e de culturas diferentes, evitando assim, que o choque cultural, traga resultados ruins para os atores envolvidos, comprometendo um dos principais objetivos do turismo voluntário, que é impactar positivamente ambas as partes.

Certamente, pessoas capacitadas para executar tarefas, das mais simples às mais complexas, tornam-se mais confiantes e, consequentemente, mais comprometidas, e com o trabalho voluntário, não é diferente. Assim, o turista voluntário que passa por uma conscientização, fica apto para a prática do volunturismo, além de tomar ciência do que encontrará no destino por ele escolhido e qual será a melhor maneira de se comportar diante de algum eventual problema que possa reduzir a qualidade da atividade que será desenvolvida junto à comunidade local.

A partir das leituras sobre turismo voluntário é possível inferir que, geralmente, o volunturista já praticou o turismo tradicional e busca algo inusitado, devendo sempre respeitar os costumes e tradições locais, chegando de coração aberto, preparados para as mais remotas situações que possam surgir, dispostos a conviver, mesmo que por pouco tempo, em locais com pouco conforto e infraestrutura, ou até sem nenhum dos dois e, ao optarem por projetos pagos, geralmente pagam uma taxa de contribuição para algum projeto local, onde estão incluídas hospedagem e alimentação em alguma ONG ou residência da comunidade destino.

A produção desse artigo teve a intenção de atrair a atenção para a necessidade de fortalecimento do debate sobre o turismo voluntário, baseando-se no seu caráter de agente transformador social. A pesquisa é inicial, discute conceitos, traz um debate teórico buscando o entendimento dessa prática turística. Poderá (e deverá) ser complementada com novos estudos que busquem uma discussão mais prática, com estudos de caso, pesquisas com volunturistas e agências e organizações que trabalham com o volunturismo. 


\section{Referências}

ALVES, J.E.D. A Terra no Limite. Revista Veja. Especial Sustentabilidade. Editora Abril, (Edição Especial), v. 43, n. 2196, dez., 2010.

ANDERECK, K. et al. Experience expectations of prospective volunteers tourists. Journal of Travel Research, v. 51, n. 2, p. 130-141, Mar. 2012. Disponível em: $<$ https://www.researchgate.net/publication/258160886 Experience Expectations of Prospective Volunteer Tourists>. Acesso em: 14 Maio 2016.

ASSISTÊNCIA MÉDICA INTERNACIONAL - AMI. A AMI. 2016. Disponível em: <https://ami.org.pt/a-ami/>. Acesso em: 10 mai. 2016.

ASSOCIATION FOR TOURISM AND LEISURE EDUCATION - ATLAS. 2008. Volunteer Tourism: A global analysis. DA Arnhem, Netherlands: ATLAS, 2008.

BARRETO, M. Planejamento Sustentável do Turismo. Campinas, SP: Papirus, 2005. (Coleção Turismo).

BIRREL, I. Before you pay to volunteer abroad, think of the harm you might do. $2010 . \quad$ Disponível em: $<$ http://www.theguardian.com/commentisfree/2010/nov/14/orphans-cambodiaaids-holidays-madonna >. Acesso em: 23 mai. 2016.

BRASIL. LEI № 9.608, DE 18 DE FEVEREIRO DE 1998. 1998. Dispõe sobre o serviço voluntário e dá outras providências. Disponível em: <http://www.planalto.gov.br/ccivil 03/leis/L9608.htm>. Acesso em: 26 mai. 2016.

CHIAVENATO, I. Recursos Humanos: o capital humano das organizações. 8. ed. 4. Reimpr. São Paulo: Atlas, 2008.

ECODESENVOLVIMENTO - ECOD. EcoD Básico: Turismo Voluntário. 2012. Disponível em: <http://www.ecodesenvolvimento.org/posts/2012/fevereiro/ecodbasico-turismo-voluntario?tag=voluntariado >. Acesso em: 26 mai. 2016.

FROSSARD, M. Armação dos Búzios - RJ: De vila de pescadores a destino turístico internacional: avaliação preliminar dos impactos da atividade turística. Anais. VIII Encontro Nacional de Turismo com Base Local. Curitiba, PR, 2004.

GLOBAL VOLUNTEERS. About us. 2016. Disponível em: $<$ www.globalvolunteers.org > . Acesso em: 18 mai. 2016.

GÓMEZ, D.M.; CANALS, A.R. Turismo solidario y volunturismo. 2012. Disponível em: <www.es.slideshare.net/Tea-Cegos Consultur/turismo-solidarioy-volunturismo>. Acesso em: 17 mai. 2016.

GROPPO. L.A.; ZAMARIAN, M.J. Juventude e Voluntariado: considerações sobre o novo modelo de participação social e os jovens no Brasil. 2009. Disponível em: <http://webcache.googleusercontent.com/search?q=cache:IYZnbmoJ8FgJ:www. sbsociologia.com.br/portal/index.php\%3Foption\%3Dcom docman\%26task\%3Dd oc download\%26gid\%3D3609\%26Itemid\%3D170+\&cd=1\&hl=ptBR\&ct=clnk\&gl=br>. Acesso em: 24 mai. 2016.

GUTTENTAG, D. (2009). The possible negative impacts of volunteer tourism. International Journal of Tourism Research. 11, 537-551. Disponível em: $<$ http://onlinelibrary. wiley.com/doi/10.1002/jtr.727/abstract;jsessionid=733E08D7 962BB12363226E3E0E2B778E.f01t01>. Acesso em: 23 mai. 2016. 
INGRAM, J.M. Volunteer Tourism: Does it have a place in Development? $2008 . \quad$ Disponível em: $<$ http://eprints.utas.edu.au/9349/2/Honours Thesis 2008.pdf >. Acesso em: 25 abr. 2016.

MAPAS ACADÊMICOS. Mapa Mundi. 2016. Disponível em: $<$ http://mapasacademicos.com.br/site/2016/12/11/download-arquivos-shapefilese-kml-mapa-mundi/\#more-175>. Acesso em 12 jan. 2018.

MARQUES, C. Diferença entre Turismo Voluntário e Turismo Solidário. 2013. Disponível em: <http://raizesdomundo.com/2013/05/25/diferenca-turismovoluntario-e-turismo-solidario/>. Acesso em: 20 set. 2015.

MAZZI, C. No turismo voluntário, respeitar costumes de outros países é fundamental. Revista Boa Viagem. O Globo, 2016. Disponível em: $<$ https://oglobo.globo.com/boa-viagem/no-turismo-voluntario-respeitarcostumes-de-outros-paises-fundamental-17508579 >. Acesso em: 14 jan. 2018.

MENDES, T.; SONAGLIO, K.E. Volunturismo: Uma Abordagem Conceitual. Revista Turismo - visão e ação. Vol. 15 - no 2 - p. 185-205 / mai-ago 2013. Disponível

em: $<$ http://siaiap32.univali.br/seer/index.php/rtva/article/view/3806/2614>. Acesso em: 10 abr. 2016.

NAÇÕES UNIDAS NO BRASIL - ONU BR. O trabalho voluntário e a ONU. 2016. Disponível em: <https://nacoesunidas.org/vagas/voluntariado/>. Acesso em: 23 mai. 2016.

NUNES, B. Alunos de colégio brasileiro trocam viagem de formatura por volunturismo. $2015 . \quad$ Disponível em: $<$ http://www.hypeness.com.br/2015/09/alunos-de-colegio-brasileiro-trocamviagem-de-formatura-por-volunturismo/>. Acesso em: 01 jun. 2016.

PORTAL DE AMÉRICA. Volunturismo: una tendencia en alza. 2011. Disponível em:

$<$ http://www.portaldeamerica.com/index.php/pda/destinos/item/5848-

volunturismo-una-tendencia-en-alza>. Acesso em: 17 mai. 2016.

PROGRAMA DAS NAÇÕES UNIDAS PARA O DESENVOLVIMENTO - PNUD. Relatório do Desenvolvimento Humano 2015: O trabalho como motor do desenvolvimento humano. 2015. Disponível em: $<$ http://hdr.undp.org/sites/default/files/hdr15 overview pt.pdf>. Acesso em: 31 mar. 2016.

RUSCHMANN, D. Turismo e planejamento sustentável: a proteção do meio ambiente. São Paulo: Papirus, 2000.

SACHS, J. A riqueza de todos: a construção de uma economia sustentável em um planeta superpovoado, poluído e pobre. Rio de Janeiro: Nova Fronteira, 2008.

SERRA, M. Mariana Serra: depoimento [2016]. Entrevistadores: Pablo Braga de Souza e Antônia Maria Nascimento Barcelos. Nova Iguaçu. Entrevista concedida por e-mail.

SIN, H.L. Volunteer tourism - "involve me and I will learn"? Annals of Tourism Research. 2009. vol. 36, No. 3, 480-501. 
TRIGUEIRO, A. Brasil tem 16,4 milhões de voluntários. É pouco. 2014. Disponível em: <http://g1.globo.com/natureza/blog/mundosustentavel/post/brasil-tem-164-milhoes-de-voluntarios-e-pouco.html>. Acesso em: 29 mar. 2016.

VOLUNTOURISM. What is VolunTourism? 2016. Disponível em: <http://www.voluntourism.org/inside-faqs.html\#1>. Acesso em: 28 abr. 2016.

WORLD COMISSION ON ENVIRONMENT AND DEVELOPMENT - WCED. Relatório Brundtland - Our Common Future. 1987. Disponível em: $<$ https://ambiente.files.wordpress.com/2011/03/brundtland-report-our-commonfuture.pdf>. Acesso em: 24 mar. 2016.

WORLD TOURISM ORGANIZATION - WTO. Handbook on tourism product development. Madrid: Ed. WTO, 2011.

\section{Notas:}

1 Organização norte-americana criada em 2004 por David Clemmons cuja missão é educar, capacitar, e se engajar em práticas de turismo voluntário (VOLUNTOURISM, 2016).

O presente artigo decorre do trabalho de conclusão do curso de Gestão de Turismo do CEFET/RJ defendido pelos autores no primeiro semestre de 2016, que recebe o mesmo título do artigo.

Pablo Braga de Souza: Centro Federal de Educação Tecnológica Celso Suckow da Fonseca, Rio de Janeiro, RJ, Brasil.

E-mail:souzapb@gmail.com

Antônia Maria Nascimento Barcelos: Centro Federal de Educação Tecnológica Celso Suckow da Fonseca, Rio de Janeiro, RJ, Brasil.

E-mail: maranascimento.ts@gmail.com

Link para o currículo Lattes: http://lattes.cnpq.br/5141340285431047

Suellen Alice Lamas: Centro Federal de Educação Tecnológica Celso Suckow da Fonseca, Rio de Janeiro, RJ, Brasil.

E-mail: suellen.lamas@cefet-rj.br

Link para o currículo Lattes: http://lattes.cnpq.br/6071263211226854

Data de submissão: 08 de novembro de 2016

Data de recebimento de correções: 07 de dezembro de 2017

Data do aceite: 07 de dezembro de 2017

Avaliado anonimamente 